\title{
Risk assessment for sustainability on telecom supply chain: A hybrid fuzzy approach
}

\author{
Venkateswarlu Nalluri ${ }^{\mathrm{a}}$ and Long-Sheng Chen ${ }^{\mathrm{a}^{*}}$
}

${ }^{a}$ Department of Information Management, Chaoyang University of Technology, Taiwan (R.O.C.)

\begin{tabular}{l}
\hline A B S T R A C T \\
\hline Article history: \\
Received September 19, 2021 \\
Received in revised format \\
October 24, 2021 \\
Accepted November 172021 \\
Available online \\
November 192021 \\
\hline Keywords: \\
Sustainability risk \\
Risk assessment \\
Mixed- fuzzy approach \\
Sustainability supply chain \\
management (SSCM) \\
Telecom supply chain (TSC)
\end{tabular}

A B S T R A C T

Received September 19,2021

Available onlin

Sustainability risk

Risk assessment

Telecom supply chain (TSC)

\begin{abstract}
Telecom supply chain (TSC) research has determined several risk sources can happen for sustainable supply chain management (SSCM) due to their ambiguous nature. However, investigation of these risks is relatively sparse and has primarily been independent with less combinatory research, despite their interrelationships and causality. The present study aims to address that gap by an extant literature review and analysis of relationships among risk factors using a combination of fuzzy approaches. A mixed approach was used, including empirical data from private and government firms in a developing telecom sector. This research finding confirmed that economical dimension risk is major for SSCM in the TSC. In developing countries, it could help telecom service providers in determining which risk factors are critical and those that are crucially significant. As a result, they will be able to more effectively develop strategies focussing on the most affecting risk dimension for SSCM. This is the first study using a hybrid fuzzy approach that analysed interrelationships of risk factors for SSCM. Further, it gives a comprehensive view of risk assessment in the risk management context in the supply chain.
\end{abstract}

(C) 2022 Growing Science Ltd. All rights reserved.

\section{Introduction}

In the COVID-19 pandemic circumstance, numerous ambiguities influence the business operations environment of the telecom sector (Herlina \& Saputra, 2021). The globalization emergence, supply and demand fluctuations, and continually improving the competitive vibe have given bloom to supply chain management issues (Valinejad \& Rahmani, 2018). Consequently, the telecom sector is compelled to implement sophisticated tools to achieve sustainability (Muneeb et al., 2020). To empower the sustainability of TSC, telecom companies are constantly focusing on implementing various traditional methods. These methods could be the form of selecting a quality supplier, matching supply and demand, coordination, revenue sharing, and SC flexibility (Chauhan et al., 2020). Moreover, supply chain managers have an enormous degree of devotion and perseverance in effectively implementing SCM techniques to sustain in the long term and to improve the overall efficiency (Khalifa et al., 2021). However, SC is vulnerable to a variety of risks due to a complicated work atmosphere and complicated interactions among supporting individuals such as customers, telecom operators, and suppliers (Valinejad \& Rahmani, 2018). The term risk refers to the probability that an activity will have unfavourable negative consequences (Daghfous et al., 2021). It could be described as a precise expectancy of loss, the greater chance that this loss will occur higher risk. The risk could be initiated through natural disasters or man made concerns, and it could have serious consequences for the telecom sector in the form of operational complications and financial instability that affect the sustainability (Yalla et al., 2018). Also, different development activities in the telecom sector such as less supply base, smaller product life cycles, and high competition have increased the sector's familiarity with SC risks (Dewangan et al., 2017). These risks can have a significant impact on the telecom firm's short- and long-term performance. Consequently, appropriate control or risk management is essential in the telecom sector to achieve overall sustainability. Moreover, the telecom firms are mainly focusing on profitability and rapid growth rather than sustainable development (Gouda \& Saranga, 2018). As well, with growing awareness of the need to implement sustainable development goals, SSCM has received a lot of attention over the

* Corresponding author

E-mail address: 1schen@ @ cyut.edu.tw (L.-S. Chen)

(C) 2022 Growing Science Ltd. All rights reserved. doi: $10.5267 /$ j.uscm.2021.11.007 
last decade (Dike and Rose, 2017). In developing countries, the telecom sector has to record a high growth rate among all the sectors and organizations. (Kusrini \& Maswadi, 2021). On the one hand, the developments and goals of telecom companies can always have a significant influence on humans and society. On the other hand, information flow management, sustainability of supply chain, capital management, and technology, as well as inter-firm collaboration across the supply chain, are all incorporated with social and economic goals (Agbebi, 2018). In addition, there are risk factors to the safety, health within a supply chain, and in the same way, the TSC associated with the environment than ambiguity poses a significant risk and hurdles to the telecom operators (Meehan \& Pinnington, 2021).

Further, from the review of literature, there has been a rising interest in the link between risk management and SSCM. Moreover, earlier studies have rarely examined the issues of sustainability risk management (Izogo, 2017), and sustainability issues are infrequently incorporated into the TSC (Reichling \& Otto, 2017). In addition, few researchers determined the interlinked telecom services with SSCM; these are accomplished on the subject as well as on the practice identification and theoretical framework (Elgharbawy, 2020). A few scholars have studied the environmental risk in TSC (Valinejad \& Rahmani, 2018). The TSC is associated with many risk factors of sustainability in developing countries. For example, environmental issues such as radiofrequency levels in the air could damage the health of individuals, and harm an organization's reputation, resulting in decreasing sales and revenue, as well as a significant impact on corporate image. Many academics have concentrated on the theoretical framework and shifted the focus of their research to economic, social, and environmental factors (Wagner, 2015). Further, Valinejad and Rahmani (2018) dealt with other two dimensions, such as institutional and technical risk dimensions in TSC. Moreover, most studies are primarily concerned with drivers (Ramesh et al., 2019), strategic factors (Saglam et al., 2020), success and failure factors (Singh \& Guha, 2018) in the telecom sector, and (Talib \& Rahman, 2017) analysis of the key sustainability barriers to telecom services adoption in developing countries rural areas. However, the existing literature focuses on the individual dimension of risk assessment in the TSC (Li et al., 2020). This is due to an insufficient optimization problem and the risk of misleading management implications (Vij, 2019), which neither examine all risk dimensions nor examine the relationships among risks of sustainability in the TSC. There are arguments that the supply chain managers and members could also abrogate their sequence of activities if they know how risk would influence the TSC, thereby influencing the sustainability of the telecom firms (Moktadir et al., 2021). In addition, understanding the impact of risk dimensions and implementation of sustainability strategies would enable the telecom firms to estimate the resource requirements at the firm level (Luthra \& Mangla, 2018). Hence, it is important to understand the impact of systemic risk in their supply chains (Yalla et al., 2018). Theoretically, the interrelationship of systematic risk in the TSC has not been very clear, whether it is affecting the sustainability of the telecom firms or not (Rezghdeh \& Shokouhyar, 2020). Therefore, it is necessary to investigate the TSC in developing countries. Therefore, this study builds the research objectives are to be described as:

- $\quad$ To identify critical risk factors (CRFs) affiliated with a TSC by utilizing the fuzzy Delphi technique.

- To evaluate the interrelationships and classification between identified CRFs.

- To develop the hierarchical structural model, identify a cause-effect group of CRFs to provide recommendations for developing functional preventive plans to the telecom sector.

To achieve the legitimate goal, a combination of the fuzzy interpretive structural modeling (fuzzy ISM) method and the fuzzy DEMATEL method is used. At first, the labeled risk factors are validated with telecom decision-makers. In addition, fuzzy ISM is performed to create a model of the risk factors, which is then classified by fuzzy DEMATEL. Both methods use fuzzy set theory to minimize the ambiguity of the inputs.

\section{Theoretical background}

This section presents a brief background of TSC, risk management, and recognition, and followed by the basis for the proposed methodology.

\subsection{Background of TSC}

In recent years, the TSC has changed with a significant amount of uncertainty, due to rapid technological changes, high competition, fluctuations between supply and demand, and the impact of the COVID-19 pandemic. According to the previous studies, a couple of scholars have investigated sustainability in the service supply chain (Dike and Rose, 2017). In addition, most of the studies on SSCM in the literature include economic and environmental aspects (Munyimi and Chari, 2018) and (Kara et al., 2020) developed the theoretical framework in TSC. Moreover, (Ramesh et al., 2019) have studied key barriers of sustainability implementation in developing countries. (Pramod et al., 2016) analysed barriers to the telecom service adoption in rural areas and has been highly indicative to telecom professionals and researchers for future research directions toward TSC risk assessment (Luthra and Mangla, 2018). Other researchers have been focused on the development of sustainability models (Khot and Thiagarajan, 2019), validation of models (Sacco, 2020), development of the theory (Muneeb et al., 2020) in developed countries. According to (Chauhan et al., 2020) selecting the quality supplier, lack of technology, changing the demand levels are the most influencing factors of sustainability in the telecom sector. (Izogo, 2017) have investigated the SSCM to improve the quality services on telecom customer perspective in India. Based on the review of 
literature, it is clear that there are many types of research in relevant areas such as the adoption of telecom services, telecom service in rural areas, service quality, manufacturing resources, and selection of quality suppliers (Ganguly, 2019). Although the telecom industry is fast evolving into one of the most inventive and advanced sectors in the global pandemic scenario. Moreover, the adoption of telecom and mobile internet services is continuously increasing, and in general, these services are increasingly reliant on social and commercial dimensions, usually considering the telecom's supply chain rigidity. While rapid technological change and the necessity of delivering services in this industry business create uncertainties and problems for the sustainability of the TSC (Jain et al., 2020). Hence, almost no studies are conducted on risk assessment in the context of SSCM on TSC within or outside developing markets.

\subsection{Risk management}

Technological advancements and dynamic transformations have increased the source of risk in the business environment. This brings in the need for proficient management and sustainability measures to control the risk. In addition, risk management is a systematic procedure that helps sectors to recognize what is a risk, who would be at risk, what are the current regulators for those risks exist, and clauses that should be issued regarding whether these authorities are appropriate or not (Rezghdeh \& Shokouhyar, 2020). However, risk management refers to the planning, monitoring, and control of activities based on risk assessment information (Norrman \& Wieland, 2020). It is a comprehensive procedure for analysing and controlling risk. In addition, instituting adequate risk management inside of sectors has been a legitimate requirement above and any ethical practice in the TSC (Rezghdeh \& Shokouhyar, 2020). Furthermore, risk management faces the challenge of managing a catalog of risks present within the TSC in developing countries (Yalla et al., 2018).

\subsection{Foundation and supply chain risk recognition}

The possible repercussions of risks might have an impact on the SSCM of TSC. Besides, every effort at management must be made to prevent risk factors and their consequences. By considering SSCM as a connection of risks, a corporate strategic objective of a company is to choose which risks are essential to achieve sustainability in its supply chain and operations. In addition, those companies are struggling with how to transfer those risks to the surrounding environment and strengthen their value proposition of regular customers (Afifa \& Saleh, 2021). Generally, the risk is nothing but the uncertainty of an event or activity throughout the TSC (Jain et al., 2020). The risk affects the day-to-day operations within the organization, often disturbing the information flow among the TSC members, and climate change (Hameed et al., 2020). This study carried out a systematic literature review to investigate the risk assessment in two phases. Few studies noted the potential factors in the telecom sector literature. For example, the critical factors like high cost of raw materials, limited sustainability literacy, limited infrastructure, lack of government support, costs, lack of education, security, legal issues, and human capital deficiency (Chowdhury et al., 2019). The legal and regulatory issues, a lack of adequate investment in infrastructure expansion, a lack of education and technical skills, poor performance and profitability, corruption and insecurity, and a lack of financial resources and high cost are identified with different names and titles in the telecom sector. Nevertheless, hardly a few scientific studies that particularly examine the risk factors for SSCM in the telecom sector have been identified. As a result, each scientific paper is thoroughly reviewed, and risk factors are identified based on their frequency of occurrence and heterogeneity. This procedure encompasses the various names and titles that are regularly used in the telecom sector. Hence, a total of 11 common risk factors were identified as shown in Table 1.

\section{Table 1}

List of supply chain risks related to sustainability

\begin{tabular}{|c|c|c|c|}
\hline No. & Risk factors & Brief outline & Source \\
\hline \multicolumn{2}{|l|}{$\mathrm{R} 1$} & $\begin{array}{l}\text { This aspect focuses on the negative consequences of unethical activities on telecom } \\
\text { firms. }\end{array}$ & $\begin{array}{l}\text { Gupta and Jain, (2019); Chen et } \\
\text { al., (2021) }\end{array}$ \\
\hline $\mathrm{R} 2$ & Suppler quality issues & $\begin{array}{l}\text { Suppler-side quality issues might impact the sustainability of supply chain efficiency, } \\
\text { from an organization's point of view. }\end{array}$ & $\begin{array}{l}\text { Jain and Raj, (2021); Ahmadi et } \\
\text { al., (2017) }\end{array}$ \\
\hline $\mathrm{R} 3$ & $\begin{array}{l}\text { Lack of education and technical } \\
\text { skills }\end{array}$ & $\begin{array}{l}\text { Understanding advanced technologies and procedures among partners requires a range } \\
\text { of technical capabilities that must be uniformly enforced and dynamically across the } \\
\text { supply chain. }\end{array}$ & $\begin{array}{l}\text { Rezghdeh and Shokouhyar, } \\
\text { (2020); Song et al., } 2017\end{array}$ \\
\hline $\mathrm{R} 4$ & $\begin{array}{l}\text { Impact of rapid change of } \\
\text { technology }\end{array}$ & $\begin{array}{l}\text { The rapid technological improvements of this factor constitute a serious obstacle to } \\
\text { the survival of the telecom sector. }\end{array}$ & $\begin{array}{l}\text { Song et al., (2017); Giannakis } \\
\text { and Papadopoulos, (2016) }\end{array}$ \\
\hline R5 & $\begin{array}{l}\text { Lack of telecom infrastructure in } \\
\text { semi-rural or rural areas }\end{array}$ & $\begin{array}{l}\mathrm{n} \text { This aspect relates to the lack of infrastructure in semi-rural and rural areas, such as } \\
\text { electricity, skilled labour, roads, and resources. }\end{array}$ & $\begin{array}{l}\text { Sacco, (2020); Talib and } \\
\text { Rahman, (2017) }\end{array}$ \\
\hline R6 & $\begin{array}{l}\text { Difficulty in import technology } \\
\text { and process }\end{array}$ & $\begin{array}{l}\text { This aspect refers to the problems in effectively re-engineering the existing system } \\
\text { when the firm imports technology from another country. }\end{array}$ & $\begin{array}{l}\text { Chen et al., (2021); Talib and } \\
\text { Rahman, (2017) }\end{array}$ \\
\hline R7 & $\begin{array}{l}\text { Change of customers } \\
\text { expectations }\end{array}$ & $\begin{array}{l}\text { This aspect leads to continuous change in customer preferences and needs; increase in } \\
\text { customer expectations in the market due to competition and service quality. }\end{array}$ & $\begin{array}{l}\text { Rezghdeh and Shokouhyar, } \\
\text { (2020); Song et al., } 2017\end{array}$ \\
\hline $\mathrm{R} 8$ & $\begin{array}{l}\text { Government policies (laws and } \\
\text { regulations) }\end{array}$ & $\begin{array}{l}\text { This aspect refers which prevents widespread adoption of telecom services in } \\
\text { developing markets is impacted by legal and regulatory issues. }\end{array}$ & $\begin{array}{l}\text { Yalla et al., (2018); Chen et al., } \\
\text { (2021) }\end{array}$ \\
\hline R9 & Market competition & Incorrect or unexpected demand prediction; vague due to era of global competition. & $\begin{array}{l}\text { Chen et al., (2021); Valinejad } \\
\text { and Rahmani, (2018) }\end{array}$ \\
\hline R10 & $\begin{array}{l}\text { Health effects of } \\
\text { electromagnetic radiations }\end{array}$ & $\begin{array}{l}\text { Working in unsafe conditions and using hazardous substances endangers human } \\
\text { health and safety in the supply chain. }\end{array}$ & $\begin{array}{l}\text { Rezghdeh and Shokouhyar, } \\
\text { (2020); Chen et al., (2021) }\end{array}$ \\
\hline R11 & Environmental pollution & Air, soil, water, or other pollution due to facility services or operations. & $\begin{array}{l}\text { Hameed et al., (2020); Talib } \\
\text { and Rahman, (2017) }\end{array}$ \\
\hline
\end{tabular}




\subsection{Foundation for the hybrid fuzzy approach}

Earlier studies have concentrated on a variety of approaches to risk assessment in the supply chain and possible approaches for mitigation. The systematic methodologies, probabilistic graphical approaches, analytical, and structural techniques were used in these studies. As per the (Chauhan et al., 2020), ISM is a well-known mechanism for accomplishing structural analysis of a complicated issue or system containing many variables, and it visually displays relationships based on numerical means (Jain and Raj, 2021). Chen et al., (2021) used this methodology to evaluate the interrelationships between the risks in the telecom sector. This ISM-based methodology has drawbacks such as subjectivity of the expert's judgment and failing to classify the risk factors. Moreover, Panjehfouladgaran and Lim, (2020) develop a risk mitigation model in the supply chain by analysing different barriers and recognizing the cause-effect categories by using the DEMATEL method. Thus, the advantage of fuzzy theory to risk assessment has been gaining acceptance among supply chain researchers (Chaudhuri et al., 2016). the fuzzy DEMATEL was used to determine a cause-effect analysis of several types of risks in the Indian textile retail supply chain (Moktadir et al., 2021). Kausar et al., (2017) deployed ISM and DEMATEL methods have been used to investigate the interrelationships between affecting factors to project communications, while it is noted both traditional methods' drawbacks could be overcome through fuzzy theory. Therefore, the present proposed hybrid fuzzy methodology would overcome the drawback of the previous studies and analyse the risk assessment of sustainability in the TSC. Shakerian et al. (2020) interactions among cognitive factors affecting unsafe behaviour with the use of a fuzzy ISM and fuzzy DEMATEL approach in the supply chain. This approach has been a useful mathematical tool to scholars and industry experts in many sectors. Hence, the present study proposes a fuzzy hybrid methodology for risk assessment of sustainability in TSC.

\section{Methodologies of the study}

Interpreted the above conditions, this study has applied a hybrid approach that included both fuzzy ISM and fuzzy DEMATEL. Where the fuzzy ISM has been used to prioritize factors. Furthermore, the fuzzy DEMATEL technique was implemented to determine the priority and intensity of quantified relationships among factors identified. Moreover, the hybrid modelling approach is a systematic thinking and analysis tool for interpreting criteria or risk factors that happen in the supply chain management and sustainability literature, which was used by (Shakerian et al., 2020). Theoretically, SSCM is regarded as a very complex system that incorporates several interdependent risk factors. Consequently, Kausar et al., (2017) proposed a model that fails to account for these interactions and cannot be used for analysis. Therefore, an approach that combines fuzzy ISM and fuzzy DEMATEL was proposed. In addition, both methods appear to be effective tools for permitting hierarchical structures and provide a clear display of the interactions within the system (Shanker et al., 2021). As stated above, the hybrid methodology was adapted to assess the risk on TSC and is as shown in Fig. 1.

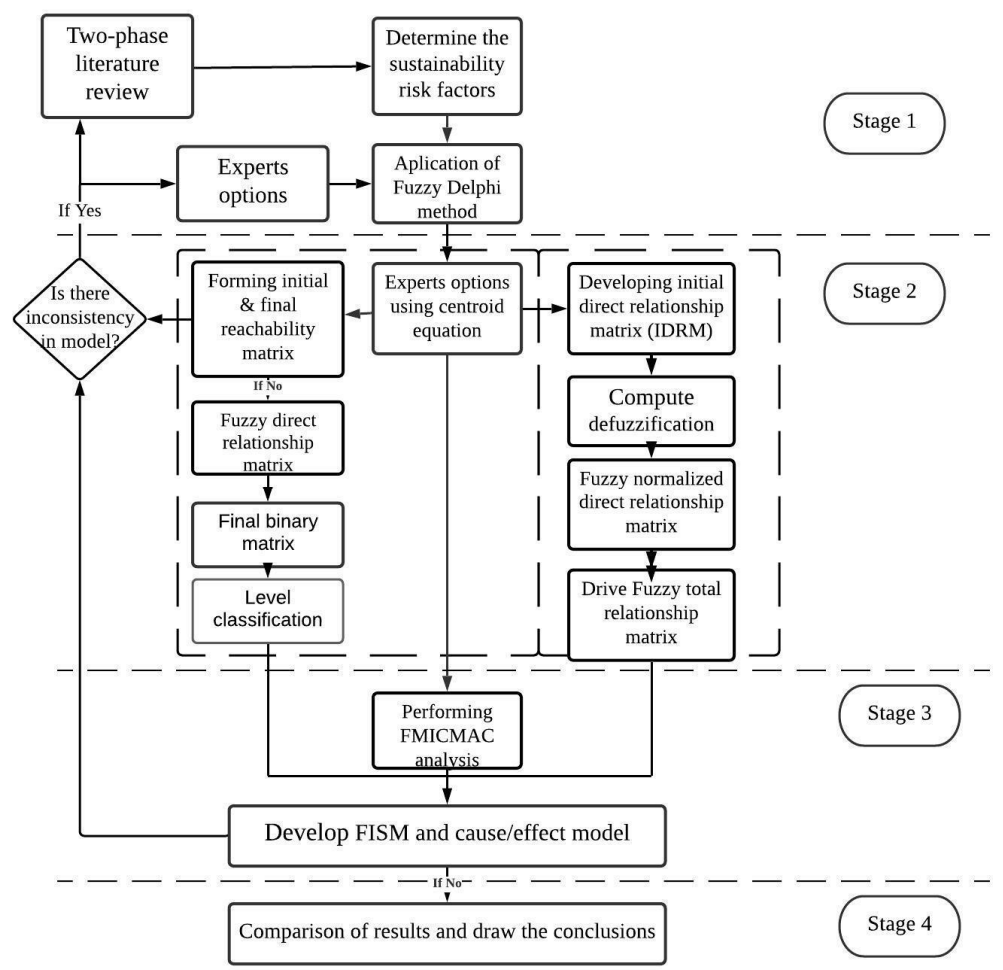

Fig. 1. Study flow chart 
As researchers stated previously, the major feature of the fuzzy ISM method is that it converts poorly and hazy adaptive system models into visible and well-defined structures (Jain and Raj, 2021). Moreover, ISM has been plagued by a variety of limitations. For instance, the decision-makers have a subjective bias in evaluating the factors, as the interrelationships between the factors are always based on that industry, its processes, awareness with the organization, and person's knowledge. This subjectivity will have a direct impact on the final finding (Singh and Guha, 2018). Similarly, the strength of the interrelationships is not considered as a result no weights are assigned to the variables. assigned to the variables. Therefore, the fuzzy DEMATEL was used to address the drawbacks of the ISM method. This hybrid approach was successfully applied by different sectors, like Ortiz-Barrios et al., (2020) for analysing sustainability in the mining industry, Nasrollahi et al., (2021) for assessment of supplier's selection for the textile and clothing industry in developing countries.

In this study, the authors collected the data in different steps from the telecom sector in India to evaluate the risk assessment of sustainability in the TSC as shown in Table 2. Moreover, it is showing that the decision-makers come from public and private firms from the telecom sector. Most of the decision-makers have worked in SCM for more than two years at their present organizations and a majority of them had more than ten years of working experience in the telecom sector. In addition, all decision-makers graduated from well-known universities and business schools in India. Based on the decision maker's assessment, this study interprets the risk factors by using fizzy ISM and Fuzzy DEMATEL methods.

Table 2

Assessment of data collection in present study

\begin{tabular}{|c|c|c|c|c|c|c|c|}
\hline \multirow{3}{*}{ Stage } & \multirow{3}{*}{$\begin{array}{l}\text { Sample } \\
\text { size }\end{array}$} & \multicolumn{5}{|c|}{ Decision-makers characteristics } & \multirow{3}{*}{ Purpose of the data collection } \\
\hline & & \multicolumn{2}{|c|}{ Firm category } & \multirow{2}{*}{$\begin{array}{c}\text { Education } \\
\text { level }\end{array}$} & \multirow{2}{*}{$\begin{array}{c}\text { Work } \\
\text { experience }\end{array}$} & \multirow{2}{*}{$\begin{array}{l}\text { Working in } \\
\text { in SCM }\end{array}$} & \\
\hline & & Public & Private & & & & \\
\hline 1 & 36 & 13 & 23 & Graduated & $>10$ years & $>2$ years & To confirm and finalize critical risk factors. \\
\hline 2 & 17 & 8 & 9 & Graduated & $<10$ years & $>2$ years & To assess the risk dimensions. \\
\hline 3 & 24 & 11 & 13 & Graduated & $>10$ years & $<2$ years & To interpret the interrelationships and cause/effect. \\
\hline
\end{tabular}

\subsection{Stage-1: Finalizing the CRFs}

In stage 1, an initial set of risk factors for evaluating the sustainability in the TSC was identified through a two-phase extensive literature review as depicted in Table 1. Following a rigorous process, the fuzzy Delphi method (FDM) was applied to the preliminary list of risk factors to determine the most relevant ones. To improve the effectiveness and reliability of questionnaires, FDM was used to reach a group decision by removing the fuzziness of expert judgments (Garg et al., 2017). Thereby, the advantage of FDM is decreasing the number of samples, the time of investigation, and providing a clearer expression of the decision-maker's knowledge. In simple words, the FDM can also be used to reshape expert opinions into quantified data to generate additional benefits and meet demand in terms of decision-making time and cost. Therefore, the FDM was adapted to find the critical risk factors (CRF's) based on expert assessments from the telecom sector (Chen et al., 2021).

\subsection{Stage-2: Performing the fuzzy ISM and DEMATEL methods}

\subsubsection{Fuzzy ISM analysis process}

Warfield (1974) developed the ISM method, which is a method of interactive learning that identifies the transitive and direct interactions among the recognized variables. Thereafter, fuzzy ISM was introduced to overcome the problems of expert subjectivity. In addition, (Srivastava and Dashora, 2021) study was utilized to model electronic traceability in agri-food supply chain in India. However, Giannakis and Papadopoulos (2016) have applied fuzzy ISM to examine the interrelationships between barriers in the telecom sector in India. Furthermore, Digalwar et al., (2020) have used the combination of ISM and ANP for analysing service adoption obstacles in the TSC, but they surveyed the rural area in India. Moreover, all the above studies were ignored CRF's of sustainability and their interrelationships for the TSC. Therefore, this study referred to the fuzzy ISM analysis process from Srivastava and Dashora, (2021).

Further, All CRFs are based on a discussion with decision-makers at the outset, followed by the FDM result being clarified for exclusiveness and exhaustiveness. In addition, there is a scope for further research to analyze the interrelationships among CRF's. Hence, the decision-makers in the second step carried out pairwise comparisons of CRF's on a fuzzy scale (Kundu, 2021) and shown in Table 2. The fuzzy ISM analysis process has followed the steps as below:

Step-1: Developing a final fuzzy reachability matrix (FFRM) by incorporating the contextual relationships by decisionmakers from the telecom sector.

Step-2: A fuzzy direct relationship matrix (FDRM) was obtained from FFRM using a computer-based program. 
Step-3: Form a final binary matrix (FBM) from FDRM by converting the crisp value (CV) values into binary form.

Step-4: Level classification is used to give levels to the CRF's.

Step-5: The development of a fuzzy ISM network is checked and reviewed for any theoretical irregularity.

Step-6: Prepared the fuzzy MICMAC matrix based on the driving and dependence powers of the CRF's.

\subsubsection{Fuzzy DEMATEL analysis process}

Further, the fuzzy DEMATEL was applied to overcome the drawbacks of the fuzzy ISM method. In addition, building an extended crisp for decision-making problems in a fuzzy environment, the multi-criteria decision-making (MCDM) technique is needed. Farooque et al. (2020) used the DEMATEL method by unifying triangular fuzzy numbers with five linguistic terms as shown in Table 3.

Table 3

Fuzzy scale of strength

\begin{tabular}{ccc}
\hline Linguistic terms & Linguistic values \\
No influence (No) & $(0,0,0.25)$ & $(0,0.25,0.5)$ \\
Very low influence (VL) & $(0.25,0.5,0.75)$ & $(0.5,0.75,1)$ \\
Low influence (L) & $(0.75,1,1)$ \\
High influence (H) & Very high influence (VH) & \\
\hline
\end{tabular}

The inputs of the decision-makers inputs were subjective, as a result, there are few ambiguities and inaccuracies. The fuzzy set theory can effectively deal with inaccuracies and ambiguity. Thus, to make use of the capability of fuzzy sets, this study integrates the fuzzy number with traditional ISM and DEMATEL approaches. Likewise, the trapezoidal numbers and triangular fuzzy numbers (TFNs) have been used in MCDM methods (Meethom \& Koohathongsumrit, 2020). The present study is utilizing the TFN's for ease of analysis. Hence, the fuzzy DEMATEL analysis procedure is subdivided into the following steps (Nasrollahi et al., 2021):

Step1: Obtaining the influence matrix for linguistic assessment

The decision-makers inputs are used to create the linguistic influence assessment matrix, which employs a five-point fuzzy scale as shown in Table 2. Each decision-maker was asked to assess the impact of one CRF on the other CRFs. The xij represents the influence of $\mathrm{CRF} i$ over $\mathrm{CRF} j$. The diagonal elements of the direct inflectional matrix should be noted (i.e. $\mathrm{i}=$ $\mathrm{j}$ ) is zero (i.e. $0,0,0)$. The individual decision-makers generate a non-negative $\mathrm{n} \times \mathrm{n}$ matrix as Xk $=[\mathrm{xkij}]$. Therefore, the $\mathrm{N}$ number of matrices $(\mathrm{X} 1, \mathrm{X} 2 \ldots \mathrm{XN})$ is obtained from $\mathrm{N}$ decision-makers.

Step-2: Developing the fuzzy initial direct relation matrix (A)

Fuzzy linguistic terms had been used to express the fuzziness in the judgments (Ahmadi et al., 2020). Each linguistic value was expressed as No, VL, L, H, and VH to describe a fuzzy event. The parameters No, VL, L, H, and VH indicated the smallest viable, the largest possible value, and the most promising respectively. Fig. 2 is depicting a fuzzy linguistic value $\tilde{M}$ from the universe of dialogue to [0, 1] (Ahmadi et al., 2020).

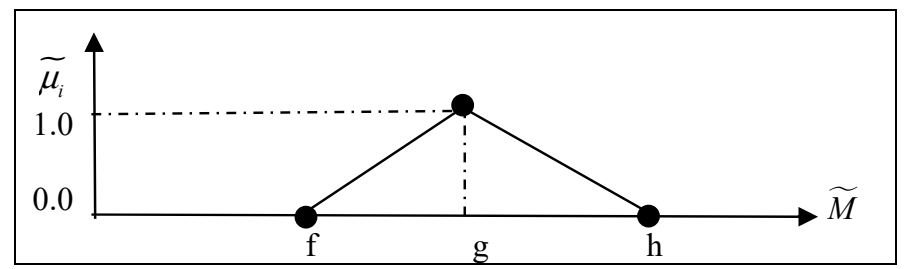

Fig. 2. Graphical representation of triangle model

The fuzzy linguistic scale is adopted as shown in Table 3. Paksoy et al. (2019) to convert impact scores to linguistic values. In addition, to explain a fuzzy event as simple as feasible for better understanding, this study proposes that each fuzzy linguistic value is stated as a triplet $(f, g, h)$. Suppose $X_{i j}^{k}=f_{i j}^{k}, g_{i j}^{k}, h_{i j}^{k}$, where $1 \leq k \leq K$ is the $k^{\text {th }}$ research participant rate of the degree to which CRF $\mathrm{i}$ influence $\mathrm{CRF} \mathrm{j}$. If ' $\mathrm{K}$ ' is the number of experts, an $\mathrm{n} X \mathrm{n}$ matrix is produced i.e. $\mathrm{k}=1,2,3,4 \ldots$. $\mathrm{n}$ (number of research participants) in Eq. (1). (Farooque et al., 2020).

$$
a_{i j}=\frac{1}{k \sum x^{k i j}}
$$


Following that, the fuzzy numbers are converted into crisp numbers in the part of the defuzzification procedure, allowing matrix operations to be undertaken. The fuzzy direct relation matrix (A) is defuzzified using Eq. (2) (Farooque et al., 2020).

$$
\mathrm{I}_{\mathrm{T}}=\frac{1}{6}(\mathrm{f}+4 \mathrm{~g}+\mathrm{h})
$$

Step-3: Remodelling the normalized initial direct relation matrix (D)

$$
\begin{aligned}
& \mathrm{m}=\min \left[\frac{1}{\max _{\mathrm{j}=1}^{\mathrm{n}}\left|\mathrm{a}_{\mathrm{ij}}\right|}, \frac{1}{\max \Sigma_{\mathrm{i}=1}^{\mathrm{n}}\left|\mathrm{a}_{\mathrm{ij}}\right|}\right] \\
& \mathrm{D}=\mathrm{m} \times \mathrm{A}
\end{aligned}
$$

Step-4: Developing the total relation matrix (Paksoy et al., 2019)

$$
\mathrm{T}=\mathrm{D}-(\mathrm{I}-\mathrm{D})^{-1}
$$

Here T: total relation matrix; I: identity matrix

Step-5: Estimating the sum of columns (C) and sum of rows (R)

$$
\begin{aligned}
& \mathrm{R}=\left[\sum_{\mathrm{j}=1}^{\mathrm{n}} \mathrm{t}_{\mathrm{ij}}\right]_{\mathrm{n} \times 1} \\
& \mathrm{C}=\left[\sum_{\mathrm{i}=1}^{\mathrm{n}} \mathrm{t}_{\mathrm{ij}}\right]_{1 \times \mathrm{n}}
\end{aligned}
$$

$\mathrm{R}$ indicated the overall influence that CRF $\mathrm{i}$ have on CRF j. C denotes the overall impact experienced by CRF $\mathrm{i}$ from $\mathrm{CRF} \mathrm{j}$.

Step-6: Preparing the cause/effect graph

The data set $(\mathrm{C}+\mathrm{R}$; $\mathrm{C}-\mathrm{R})$ was used to develop a cause-and-effect graph. The horizontal axis $(\mathrm{C}+\mathrm{R})$ is used to calculate the prominence and total effects in terms of influence and influential power. The vertical axis (C-R) depicts the cause-and-effect interaction among CRFs. A risk factor belongs to the cause category if it is (C-R) value is larger than zero. Likewise, if a risk factor's (C-R) value is less than zero, it falls into the effect category (Shanker \& Barve, 2021). Furthermore, the arrows were used to map significant relationships among CRF's on the cause-effect graph to highlight their interdependence.

\section{Findings and discussions}

This section deals with finalizing and analysing the risk of sustainability for TSC in developing countries utilizing wellknown MCDM methods with fuzzy theory.

\subsection{Fuzzy Delphi method result}

The 11 risk factors identified in Table 1. Before performing fuzzy ISM, conforms with decision-makers are further filtered to obtain CRFs for SSCM. After issuing a questionnaire to consult the respondents of telecom companies in India as shown in Table 2, a fuzzy Delphi method is utilized to finalize the CRFs. As per the FDM steps, the MIN, MEDIUM, and MAX values were calculated. Further, the decision-maker's input is transformed into fuzzy numbers, then the fuzzy values convert as defuzzification values. Dawood et al., (2021) identified the variables using the threshold value of 0.60. However, this study proposed the dimensions of the risk of sustainability as the decision-makers were suggested in the data collection process. The CRF's R3, R7 were determined as social dimensions. The CRF's R1, R2, R4, R5, R6, R8, and R9 come under the economic dimension. The environmental dimension CRF's are R10 and R11 as shown in Table 4. Therefore, this study results of the fuzzy Delphi were also taken in the range of 0.60 as shown in Table 4.

\section{Table 4}

Fuzzy Delphi method result at threshold value 0.60

\begin{tabular}{cccc}
\hline & & & \\
\hline Risk factor & Risk dimension & Defuzzification value & Threshold value $(0.60)$ \\
R1 & Economic & 0.680 & Accept \\
R2 & Economic & 0.667 & Accept \\
R3 & Social & 0.607 & Accept \\
R4 & Economic & 0.637 & Accept \\
R5 & Economic & 0.659 & Accept \\
R6 & Economic & 0.650 & Accept \\
R7 & Social & 0.646 & Accept \\
R8 & Economic & 0.727 & Accept \\
R9 & Economic & 0.780 & Accept \\
R10 & Environmental & 0.610 & Accept \\
R11 & Environmental & 0.646 & Accept \\
\hline
\end{tabular}


Further, All the CRF's has based on the initial discussion with decision-makers followed by FDM results at 0.60 (threshold value). Therefore, the fuzzy ISM approach analysis is performed as follows.

\subsubsection{Final fuzzy reachability matrix (FFRM)}

To develop the FFRM, the decision-makers were asked to compare pairwise comparisons in linguistic terms to measure the relationship among the CRF's as shown in Table 3. The factor $\mathrm{i}$ is represented by a row, and factor $\mathrm{j}$ is indicated by the column. For instance, the relationship between the risk factors R1, R7 is low so the symbol ' $L$ ' has indeed been positioned in the cell $(8,2)$. While risk factors R2, R5 are very high and so symbol 'VH' has been in the cell $(5,6)$ followed by all cells filled by decision-makers from the telecom sector as shown in Table 3. Then, we have evaluated all the decision makers' options and prepared an initial fuzzy reachability matrix as shown in Table 5.

Table 5

Final fuzzy reachability matrix

\begin{tabular}{|c|c|c|c|c|c|c|c|c|c|c|c|}
\hline CRF & $\mathrm{R} 1$ & R2 & R3 & $\mathrm{R} 4$ & R5 & R6 & R7 & R8 & R9 & R10 & R11 \\
\hline R1 & 1 & No & $\mathrm{L}$ & VL & VL & VL & $\mathrm{L}$ & No & $\mathrm{L}$ & $\mathrm{VL}$ & $\mathrm{VH}$ \\
\hline R2 & $\mathrm{H}$ & 1 & $\mathrm{H}$ & $\mathrm{H}$ & VH & $\mathrm{H}$ & $\mathrm{H}$ & $\mathrm{L}$ & $\mathrm{H}$ & $\mathrm{L}$ & $\mathrm{H}$ \\
\hline R3 & $\mathrm{H}$ & $\mathrm{H}$ & 1 & VL & No & VH & $\mathrm{L}$ & VL & $\mathrm{L}$ & No & $\mathrm{H}$ \\
\hline $\mathrm{R} 4$ & $\mathrm{H}$ & VH & $\mathrm{H}$ & 1 & $\mathrm{H}$ & $\mathrm{VH}$ & VH & VL & $\mathrm{H}$ & No & $\mathrm{H}$ \\
\hline R5 & VH & $\mathrm{L}$ & VL & VH & 1 & $\mathrm{~L}$ & VL & $\mathrm{L}$ & $\mathrm{VH}$ & VL & $\mathrm{H}$ \\
\hline R6 & $\mathrm{L}$ & VL & VH & VL & $\mathrm{L}$ & 1 & $\mathrm{~L}$ & $\mathrm{~L}$ & VL & No & $\mathrm{H}$ \\
\hline R7 & VH & $\mathrm{L}$ & VL & VL & VL & $\mathrm{L}$ & 1 & VL & VH & $\mathrm{H}$ & $\mathrm{H}$ \\
\hline R8 & VH & $\mathrm{H}$ & VH & VH & $\mathrm{H}$ & $\mathrm{VH}$ & VH & 1 & $\mathrm{VH}$ & VH & $\mathrm{H}$ \\
\hline R9 & $\mathrm{H}$ & VL & $\mathrm{L}$ & $\mathrm{L}$ & VL & $\mathrm{L}$ & $\mathrm{H}$ & VL & 1 & VH & VH \\
\hline R10 & $\mathrm{H}$ & VL & $\mathrm{L}$ & No & $\mathrm{H}$ & $\mathrm{VH}$ & VL & No & No & 1 & $\mathrm{~L}$ \\
\hline R11 & $\mathrm{VH}$ & $\mathrm{L}$ & VL & VL & $\mathrm{L}$ & VL & No & No & No & No & 1 \\
\hline
\end{tabular}

\subsubsection{Fuzzy direct relationship matrix (FDRM) (D)}

After obtaining FFRM, the fuzzy direct relationship matrix is to convert the fuzzy values into the CV. The direct relationship analysis describes the strengths of direct relationships between contextual variables (Shanker and Barve, 2021). The indirect relationship among variables may be significant in the perceiving of hidden impacts of the variables. The accumulated effect of direct and indirect relationships can be computed. Subsequently, but since direct observation makes the calculation difficult, a computer program was used to perform these steps with a stop criterion when there is no further improvement in converting CV. Therefore, the fuzzy direct relationship matrix (D) was developed as shown in Table 6.

Table 6

Fuzzy direct relationship matrix

\begin{tabular}{|c|c|c|c|c|c|c|c|c|c|c|c|}
\hline $\mathrm{CRF}$ & $\mathrm{R} 1$ & $\mathrm{R} 2$ & R3 & $\mathrm{R} 4$ & R5 & R6 & R7 & R8 & R9 & R10 & R11 \\
\hline R1 & 1 & 0.33 & 0.06 & 0.2 & 0.23 & 0.24 & 0.37 & 0.12 & 0.04 & 0.18 & $0.77^{*}$ \\
\hline $\mathrm{R} 2$ & $0.73 *$ & 1 & $0.75^{*}$ & $0.6^{*}$ & $0.57 *$ & $0.7^{*}$ & $0.58 *$ & 0.39 & $0.6^{*}$ & $0.59 *$ & $0.56^{*}$ \\
\hline R3 & $0.65^{*}$ & $0.79 *$ & 1 & $0.57^{*}$ & 0.46 & $0.7 *$ & 0.38 & 0.17 & 0.31 & 0.38 & $0.59 *$ \\
\hline R4 & $0.57 *$ & $0.59 *$ & $0.57 *$ & 1 & $0.77^{*}$ & $0.6^{*}$ & $0.59^{*}$ & 0.48 & $0.7^{*}$ & 0.47 & $0.57^{*}$ \\
\hline R5 & $0.66^{*}$ & $0.56^{*}$ & $0.56^{*}$ & $0.79 *$ & 1 & $0.56^{*}$ & 0.46 & 0.45 & $0.79 *$ & 0.48 & $0.6^{*}$ \\
\hline R6 & $0.71^{*}$ & 0.46 & $0.68 *$ & 0.34 & 0.49 & 1 & 0.38 & 0.18 & 0.27 & 0.46 & $0.59^{*}$ \\
\hline R7 & $0.59^{*}$ & 0.38 & 0.42 & 0.44 & 0.35 & $0.7^{*}$ & 1 & 0.33 & $0.57^{*}$ & $0.6^{*}$ & $0.57^{*}$ \\
\hline R8 & $0.77 *$ & $0.78^{*}$ & $0.59 *$ & $0.79 *$ & $0.97 *$ & $0.9^{*}$ & $0.77^{*}$ & 1 & $0.71 *$ & $0.78^{*}$ & $0.79^{*}$ \\
\hline R9 & $0.57^{*}$ & 0.42 & $0.56^{*}$ & 0.46 & 0.35 & $0.58^{*}$ & $0.57^{*}$ & 0.46 & 1 & $0.59^{*}$ & $0.68 *$ \\
\hline $\mathrm{R} 10$ & $0.68 *$ & 0.44 & $0.57 *$ & 0.38 & $0.77 *$ & $0.59 *$ & 0.42 & 0.09 & 0.49 & 1 & 0.38 \\
\hline $\mathrm{R} 11$ & $0.59 *$ & 0.04 & 0.26 & 0.06 & 0.12 & 0.46 & 0.46 & 0.04 & 0.06 & 0.1 & 1 \\
\hline
\end{tabular}

*Mark indicates $\geq 0.54$

\subsubsection{Fuzzy binary matrix (S)}

In addition, we have calculated the threshold value $(\alpha)$ to identify the low and high strengths based on matrix D. Then, the final binary matrix was prepared based on the fuzzy direct relationship matrix by assigning zero values for less than the threshold value $(\alpha) 0.54$, and values of one to equal or greater than 0.54 . For example, the crisp values of the R3 and R4 are 0.33 in FDRM as Table 7 , which is less than the $\alpha$ value $(0.54)$. Therefore, the cell $(3,2)$ in the final binary matrix is determined as ' 0 '. And, the crisp values of the R4 and R3 are 0.73 in FDRM, which is greater than the $\alpha$ value (0.54). Therefore, the cell $(2,3)$ in the final binary matrix is noted as ' 1 '. The same conversion rule applies to all cells in the final binary matrix (S) (Wang et al., 2018). Then, we have calculated the sum of the rows to determine the driving power of each CRF. Similarly, the column sum to determine the dependence power of all CRFs in the final binary matrix. The final binary matrix (S) is shown in Table 7. 
Table 7

Final binary matrix

\begin{tabular}{|c|c|c|c|c|c|c|c|c|c|c|c|c|}
\hline $\mathrm{CRF}$ & $\mathrm{R} 1$ & $\mathrm{R} 2$ & R3 & R4 & R5 & R6 & R7 & $\mathrm{R} 8$ & R9 & $\mathrm{R} 10$ & R11 & Driving power \\
\hline R1 & 1 & 0 & 0 & 0 & 0 & 0 & 0 & 0 & 0 & 0 & 1 & 2 \\
\hline R2 & 1 & 1 & 1 & 1 & 1 & 1 & 1 & 0 & 1 & 1 & 1 & 10 \\
\hline R3 & 1 & 1 & 1 & 1 & 0 & 1 & 0 & 0 & 0 & 0 & 1 & 6 \\
\hline R4 & 1 & 1 & 1 & 1 & 1 & 1 & 1 & 0 & 1 & 0 & 1 & 9 \\
\hline R5 & 1 & 1 & 1 & 1 & 1 & 1 & 0 & 0 & 1 & 0 & 1 & 8 \\
\hline R6 & 1 & 0 & 1 & 0 & 0 & 1 & 0 & 0 & 0 & 0 & 1 & 4 \\
\hline R7 & 1 & 0 & 0 & 0 & 0 & 1 & 1 & 0 & 1 & 1 & 1 & 6 \\
\hline R8 & 1 & 1 & 1 & 1 & 1 & 1 & 1 & 1 & 1 & 1 & 1 & 11 \\
\hline R9 & 1 & 0 & 1 & 0 & 0 & 1 & 1 & 0 & 1 & 1 & 1 & 7 \\
\hline R10 & 1 & 0 & 1 & 0 & 1 & 1 & 0 & 0 & 0 & 1 & 0 & 5 \\
\hline R11 & 1 & 0 & 0 & 0 & 0 & 0 & 0 & 0 & 0 & 0 & 1 & 2 \\
\hline Dependence power & 11 & 5 & 8 & 5 & 5 & 9 & 5 & 1 & 6 & 5 & 10 & 70 \\
\hline
\end{tabular}

\subsubsection{Level classification}

To develop the fuzzy ISM network, the final binary matrix (S) is performed the level classification. As per Dewangan et al., (2017), the final binary matrix (S) yields the first reachability set and antecedence sets as shown in Table 8 .

Table 8

Level classification

\begin{tabular}{cccc}
\hline CRF & Reachability set R & Antecedent set A & Intersection set R $\cap$ A \\
\hline R1 & R1,R11 & R1,R2,R4,R5,R6,R7,R8,R9,R10,R11 & R1,R11 \\
R2 & R2,R4,R5 & R2,R4,R5,R8 & R2,R4,R5 \\
R3 & R2,R3,R4,R6 & R2,R3,R4,R5,R6,R8,R9,R10 & R2,R3,R4,R6 \\
R4 & R2,R4,R5 & R2,R4,R5,R8 & R2,R4,R5 \\
R5 & R2,R4,R5 & R2,R4,R5,R8 & R2,R4,R5 \\
R6 & R3,R6 & R2,R3,R4,R5,R6,R7,R8,R9,R10 & R3,R6 \\
R7 & R7,R9 & R2,R4,R7,R8,R9 & R7,R9 \\
R8 & R8 & R8 & R8 \\
R9 & R4,R9 & R2,R4,R5,R7,R8,R9 & R4,R9 \\
R10 & R5,R10 & R2,R5,R7,R8,R9,R10 & R5,R10 \\
R11 & R1,R11 & R \\
\hline
\end{tabular}

A reachability set is a collection of CRFs that are driven by that CRF and factor itself. The set of CRFs that drives that CRF and factor itself is known as the antecedence set. An intersection set is a collection of CRFs that appear in both the reachability and antecedence sets (Srivastava and Dashora, 2021). Based on fuzzy ISM analysis the CRF's R1 and R11 are intersection factors after performing all three set comparisons in level 1. In the ISM hierarchy, the CRF's R1, and R11 are placed at the top level. In addition, Those CRFs are eliminated to further level partitioning, and the procedure is repeated until each CRF is assigned its level. The total process of all CRF levels is shown in Table 8.

\subsubsection{Develop ISM network}

Finally, after determining the level of CRFs and utilizing the final binary matrix (S). The structural model network is built with the aid of vertices and edges (Wang et al., 2018). Future, among these eleven CRFs set as their level. In this study, the CRF's R1, and R11 came out at the top level with low driving power, and the bottom level CRF is R8 with high driving power as shown in Table 7. All the rest of the CRF's are lying in between R8 (bottom level) and the CRF's R1, and R11 (top level). As per the above steps, an ISM network is developed and shown in Fig. 3.

\subsubsection{Fuzzy MICMAC Result}

As per Shanker and Barve, (2021) MICMAC method has been providing the classification of the system variables. In addition, the fuzzy MICMAC analysis is based on the matrix multiplication properties (Dewangan et al., 2017). The fuzzy MICMAC is used in this research to calculate the CRF's driving power and dependence power to allocate their rank.

Table 9

Based final binary matrix (S) driving power and dependence power

\begin{tabular}{|c|c|c|c|c|}
\hline $\mathrm{CRF}$ & Driving power & Dependence power & Driving power- Dependence power & Rank \\
\hline $\mathrm{R} 1$ & 2 & 11 & -9 & 10 \\
\hline R2 & 10 & 5 & 5 & 2 \\
\hline R3 & 6 & 8 & -2 & 7 \\
\hline R4 & 9 & 5 & 4 & 3 \\
\hline R5 & 8 & 5 & 3 & 4 \\
\hline R6 & 4 & 9 & -5 & 8 \\
\hline R7 & 6 & 5 & 1 & 5 \\
\hline $\mathrm{R} 8$ & 11 & 1 & 10 & 1 \\
\hline R9 & 7 & 6 & 1 & 5 \\
\hline $\mathrm{R} 10$ & 5 & 5 & 0 & 6 \\
\hline R11 & 2 & 10 & -8 & 9 \\
\hline
\end{tabular}




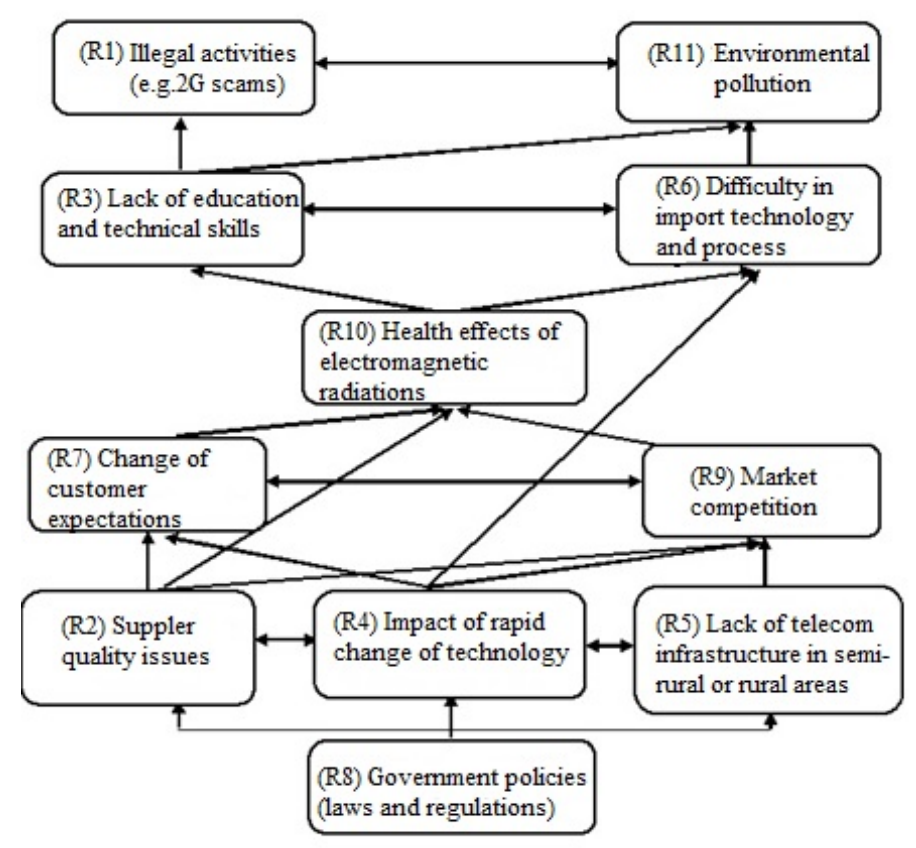

Fig. 3. ISM network

In fuzzy MICMAC analysis, which was computed as the sum of the columns and rows in the final binary matrix (S) (Table 7) as a part of fuzzy ISM analysis. Then, the difference between each CRF's driving power and dependence was calculated, and the rank of each CRF was assigned as shown in Table 9. For example, the dependence power is ' 1 ' and driving power is ' 11 ' of R8, the difference is ' 10 '. It means the CRF R8 has the highest power among all CRF's. Therefore, it was noted with rank ' 1 ', so the telecom operators could control government policies (laws and regulations) (R8) as a priority. Similarly, the ranking of the CRF's will guide the telecom company managers, which factor needs a priority to control or monitor the risk in their supply chain. Therefore, the driving-dependent power of CRF's analysis is called a fuzzy MICMAC matrix shown in Fig. 4.

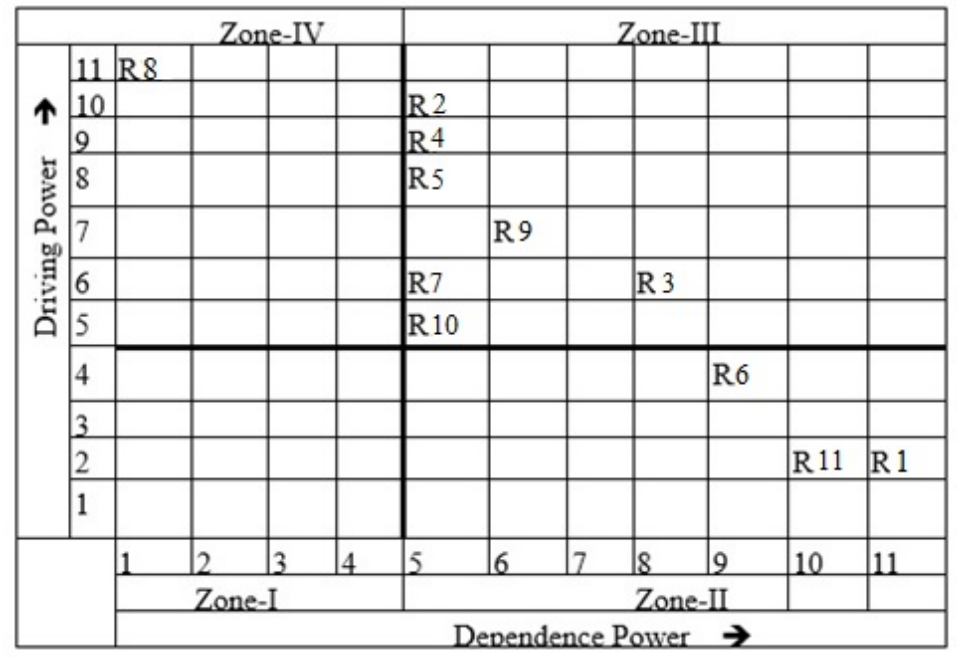

Fig. 4. Fuzzy MICMAC matrix

The CRFs are divided into four categories based on their driving power and dependence power (Yadav and Desai, 2017).

Zone I: Autonomous CRF's are those with low dependence power and driving power, and those are significantly unconnected with the system. There is none of CRF that falls in the zone I as per this study result.

Zone II: Dependent CRFs have a low driving power but a high dependence power. The CRFs R1, R11, and R6 are the dependent CRFs. 
Zone III: The CRFs with high dependence power and driving power are known as linkage CRFs. These CRFs are unique in that any action on these CRF's that may affect others could also have a feedback effect on them. The CRF's R3 and R9 are purely come out in zone III as linkage CRFs. In addition, the CRF's R2, R4, R5, and R7 are identified between zones III and IV.

Zone IV: Independent CRFs or triggering factors are those with high driving power and low dependence power. Such CRFs are typically the most significant, so gaining control of these zone CRFs may be the top priority of a company's policymaker. In this study, the CRF R8 is the independent factor. In addition, the CRF R10 is determined at the centre of the fuzzy MICMAC matrix as shown in Fig. 4. Therefore, the telecom operators must focus on the high driving power CRF's R8 and R10 also must be considered as the priority factor based on MICMAC matrix results to overcome sustainability issues in their supply chain.

\subsection{Fuzzy DEMATEL result}

In this section, to determine the causal relationship between the identified CRFs of sustainability in TSC, the fuzzy DEMATEL technique is applied. The decision-makers assessed using the linguistic scale by comparing the influence of one CRF over the other CRF as shown in Table 2. The decision-makers inputs are used to produce a pairwise matrix, which is then converted into a fuzzy relationship matrix using triangular fuzzy numbers as shown in Table 3 . Additionally, the general direct relationship matrix (A) is produced by combining the responses of decision-makers using Eq. (1) and (2) as shown in Table 10. Future, Eq. (3) and (4) yield the normalized direct-relationship matrix (D).

Table 10

Fuzzy initial direct relation matrix (A)

\begin{tabular}{ccccccc}
\hline CRF & $\mathrm{R} 1$ & $\mathrm{R} 2$ & $\mathrm{R} 3$ & $\mathrm{R} 4$ & $\mathrm{R} 5$ & $\mathrm{R} 6$ \\
\hline R1 & $(0,0,0)$ & $(0.018,0.034,0.077)$ & $(0.008,0.023,0.056)$ & $(0.012,0.018,0.065)$ & $(0.003,0.009,0.064)$ & $(0.045,0.065,0.096)$ \\
R2 & $(0.032,0.045,0.085)$ & $(0,0,0)$ & $(0.017,0.032,0.085)$ & $(0.013,0.019,0.057)$ & $(0.003,0.009,0.052)$ & $(0.063,0.103,0.136)$ \\
R3 & $(0,0.003,0.038)$ & $(0.064,0.103,0.138)$ & $(0,0,0)$ & $(0,0.013,0.064)$ & $(0.036,0.084,0.09)$ & $(0.045,0.103,0.09)$ \\
R4 & $(0.032,0.052,0.09)$ & $(0.013,0.015,0.064)$ & $(0.018,0.083,0.013)$ & $(0,0,0)$ & $(0.013,0.019,0.064)$ & $(0.013,0.038,0.064)$ \\
R5 & $(0,0.003,0.046)$ & $(0.057,0.077,0.109)$ & $(0.032,0.058,0.096)$ & $(0.032,0.051,0.09)$ & $(0,0,0)$ & $(0.038,0.064,0.109)$ \\
R6 & $(0,0.038,0.051)$ & $(0.038,0.051,0.077)$ & $(0.006,0.016,0.038)$ & $(0.045,0.065,0.096)$ & $(0,0.003,0.083)$ & $(0,0,0)$ \\
R7 & $(0.032,0.051,0.09)$ & $(0,0.003,0.044)$ & $(0.013,0.015,0.064)$ & $(0.038,0.077,0.122)$ & $(0.019,0.026,0.086)$ & $(0.077,0.09,0.122)$ \\
R8 & $(0.018,0.028,0.074)$ & $(0.015,0.018,0.053)$ & $(0.018,0.028,0.074)$ & $(0.021,0.036,0.078)$ & $(0.013,0.105,0.064)$ & $(0.021,0.038,0.078)$ \\
R9 & $(0,0.003,0.038)$ & $(0.026,0.038,0.09)$ & $(0.006,0.038,0.057)$ & $(0,0.026,0.056)$ & $(0.046,0.086,0.096)$ & $(0,0.038,0.057)$ \\
R10 & $(0,0.003,0.038)$ & $(0.032,0.058,0.096)$ & $(0.018,0.083,0.13)$ & $(0.046,0.057,0.096)$ & $(0,0.003,0.038)$ & $(0.003,0.009,0.064)$ \\
R11 & $(0.036,0.065,0.103)$ & $(0.019,0.026,0.065)$ & $(0.0570 .077,0.109)$ & $(0.034,0.047,0.085)$ & $(0.036,0.084,0.09)$ & $(0.036,0.084,0.09)$ \\
\hline
\end{tabular}

Table 10

Fuzzy initial direct relation matrix (A) (Continued)

\begin{tabular}{|c|c|c|c|c|c|}
\hline CRF & R7 & R8 & R9 & $\mathrm{R} 10$ & R11 \\
\hline R1 & $(0.045,0.067,0.105)$ & $(0.015,0.017,0.065)$ & $(0.034,0.056,0.085)$ & $(0.005,0.013,0.057)$ & $(0,0.003,0.038)$ \\
\hline $\mathrm{R} 2$ & $(0.0 .36,0.065,0.103)$ & $(0.015,0.025,0.062)$ & $(0.019,0.056,0.109)$ & $(0.066,0.105,0.74)$ & $(0.046,0.057,0.096)$ \\
\hline $\mathrm{R} 3$ & $(0.045,0.075,0.116)$ & $(0.005,0.013,0.057)$ & $(0.036,0.084,0.09)$ & $(0.018,0.028,0.074)$ & $(0.018,0.083,0.013)$ \\
\hline R4 & $(0.016,0.034,0.064)$ & $(0.015,0.018,0.053)$ & $(0,0.034,0.09)$ & $(0.008,0.023,0.056)$ & $(0.003,0.009,0.064)$ \\
\hline R5 & $(0.046,0.069,0.09)$ & $(0.017,0.032,0.085)$ & $(0.077,0.09,0.109)$ & $(0,0.026,0.056)$ & $(0.032,0.052,0.09)$ \\
\hline R6 & $(0.045,0.064,0.096)$ & $(0.018,0.083,0.130)$ & $(0,0.038,0.044)$ & $(0.032,0.058,0.096)$ & $(0.046,0.057,0.096)$ \\
\hline R7 & $(0,0,0)$ & $(0.003,0.009,0.064)$ & $(0.019,0.035,0.077)$ & $(0,0.003,0.038)$ & $(0.077,0.086,0.109)$ \\
\hline $\mathrm{R} 8$ & $(0,0.003,0.038)$ & $(0,0,0)$ & $(0.003,0.009,0.064)$ & $(0,0.013,0.064)$ & $(0.018,0.083,0.013)$ \\
\hline R9 & $(0.032,0.058,0.096)$ & $(0.013,0.015,0.064)$ & $(0,0,0)$ & $(0.032,0.058,0.096)$ & $(0.077,0.09,0.103)$ \\
\hline $\mathrm{R} 10$ & $(0.032,0.052,0.09)$ & $(0.018,0.083,0.13)$ & $(0.077,0.096,0.109)$ & $(0,0,0)$ & $(0.032,0.052,0.09)$ \\
\hline $\mathrm{R} 11$ & $(0.034,0.056,0.085)$ & $(0.057,0.077,0.109)$ & $(0.036,0.084,0.09)$ & $(0.034,0.056,0.085)$ & $(0,0,0)$ \\
\hline
\end{tabular}

Table 11

Total relation matrix

\begin{tabular}{|c|c|c|c|c|c|c|c|c|c|c|c|c|}
\hline CRF & R1 & R2 & R3 & $\mathrm{R} 4$ & R5 & R6 & R7 & R8 & R9 & R10 & R11 & $\mathrm{R}$ \\
\hline R1 & 0.106 & 0.191 & 0.174 & 0.180 & 0.145 & $0.284^{*}$ & $0.269^{*}$ & 0.166 & 0.246 & 0.157 & 0.206 & 2.125 \\
\hline $\mathrm{R} 2$ & 0.241 & 0.219 & $0.283^{*}$ & 0.265 & 0.216 & $0.439^{*}$ & $0.367^{*}$ & 0.263 & $0.358^{*}$ & $0.337^{*}$ & $0.414 *$ & 3.401 \\
\hline R3 & 0.198 & $0.382 *$ & 0.245 & $0.275^{*}$ & $0.321^{*}$ & $0.460^{*}$ & $0.407^{*}$ & 0.260 & $0.406^{*}$ & $0.281^{*}$ & $0.447^{*}$ & 3.682 \\
\hline $\mathrm{R} 4$ & 0.186 & 0.185 & 0.259 & 0.144 & 0.168 & 0.256 & 0.234 & 0.167 & 0.235 & 0.170 & 0.224 & 2.227 \\
\hline R5 & 0.185 & $0.330^{*}$ & $0.310^{*}$ & 0.299 & 0.197 & $0.397^{*}$ & $0.368^{*}$ & 0.261 & $0.396^{*}$ & 0.249 & $0.385^{*}$ & 3.378 \\
\hline R6 & 0.197 & 0.254 & 0.223 & 0.286 & 0.184 & 0.252 & $0.316^{*}$ & $0.291^{*}$ & $0.275^{*}$ & 0.255 & $0.341^{*}$ & 2.874 \\
\hline $\mathrm{R} 7$ & 0.216 & 0.186 & 0.216 & 0.289 & 0.205 & $0.366^{*}$ & 0.215 & 0.195 & $0.268^{*}$ & 0.174 & $0.351 *$ & 2.680 \\
\hline R8 & 0.153 & 0.165 & 0.188 & 0.191 & 0.151 & 0.239 & 0.175 & 0.128 & 0.183 & 0.151 & $0.286^{*}$ & 2.009 \\
\hline R9 & 0.162 & 0.261 & 0.259 & 0.240 & $0.288^{*}$ & $0.318^{*}$ & $0.325^{*}$ & 0.223 & 0.248 & 0.266 & $0.392 *$ & 2.981 \\
\hline R10 & 0.169 & $0.289 *$ & $0.325^{*}$ & $0.290^{*}$ & 0.202 & $0.306^{*}$ & $0.326^{*}$ & $0.301^{*}$ & $0.382^{*}$ & 0.191 & $0.365^{*}$ & 3.148 \\
\hline R11 & $0.280^{*}$ & $0.300^{*}$ & $0.366^{*}$ & $0.325^{*}$ & $0.328^{*}$ & $0.446^{*}$ & $0.388^{*}$ & $0.346^{*}$ & $0.416^{*}$ & $0.308^{*}$ & $0.342 *$ & 3.844 \\
\hline $\mathrm{C}$ & 2.093 & 2.764 & 2.848 & 2.783 & 2.405 & 3.762 & 3.389 & 2.600 & 3.413 & 2.538 & 3.752 & 32.347 \\
\hline
\end{tabular}

Note: $* 0.267$ 
Furthermore, Eq. (5) is used to generate the total relationship matrix (T) for each CRF, which is shown in Table 11. Using Eq. (6) and (7), the summing of columns and rows is represented by $\mathrm{R}$ and $\mathrm{C}$ respectively from the total relation matrix (T). The net influence received by $\mathrm{j}$ CRF from other CRF's is denoted by $\mathrm{Cj}$, while the total effect of CRF i to other CRF's is denoted by $\mathrm{Ri}$. After each row and column's $\mathrm{R}$ and $\mathrm{C}$ have been determined. The net cause/effect of each $\mathrm{CRF}$ has been determined based on $(\mathrm{C}+\mathrm{R})$ and $(\mathrm{C}-\mathrm{R})$ values. If $(\mathrm{C}-\mathrm{R})$ is positive, the $\mathrm{CRF}$ is considered to be the net cause, and if $(\mathrm{C}-\mathrm{R})$ value is negative, the CRF is the net effect. The cause and effect calculations are shown in Table 12. Moreover, this analysis results confirmed the CRF's R4, R6, R7, R8, and R9 as the cause group. In addition, the CRF's R1, R2, R3, R5, R10, and $\mathrm{R} 11$ are coming under the effect group based on their C-R values as shown in Table 12.

Table 12

Calculating the sum of the rows (R) and columns $(\mathrm{C}), \mathrm{C}+\mathrm{R}$, and $\mathrm{C}-\mathrm{R}$

\begin{tabular}{ccccc}
\hline CRFs & $\mathrm{C}$ & $\mathrm{R}$ & $\mathrm{C}+\mathrm{R}$ & $\mathrm{C}-\mathrm{R}$ \\
\hline R1 & 2.093 & 2.125 & 4.218 & -0.032 \\
R2 & 2.764 & 3.401 & 6.165 & -0.637 \\
R3 & 2.848 & 3.682 & 6.53 & -0.834 \\
R4 & 2.783 & 2.227 & 5.01 & 0.556 \\
R5 & 2.405 & 3.378 & 5.783 & -0.973 \\
R6 & 3.762 & 2.874 & 6.636 & 0.888 \\
R7 & 3.389 & 2.68 & 6.069 & 0.709 \\
R8 & 2.6 & 2.009 & 4.609 & 0.591 \\
R9 & 3.413 & 2.981 & 6.394 & 0.432 \\
R10 & 2.538 & 3.148 & 5.686 & -0.61 \\
R11 & 3.752 & 3.844 & 7.596 & -0.092 \\
\hline Average & 2.940 & 2.940 & 5.881 & -0.002 \\
\hline
\end{tabular}

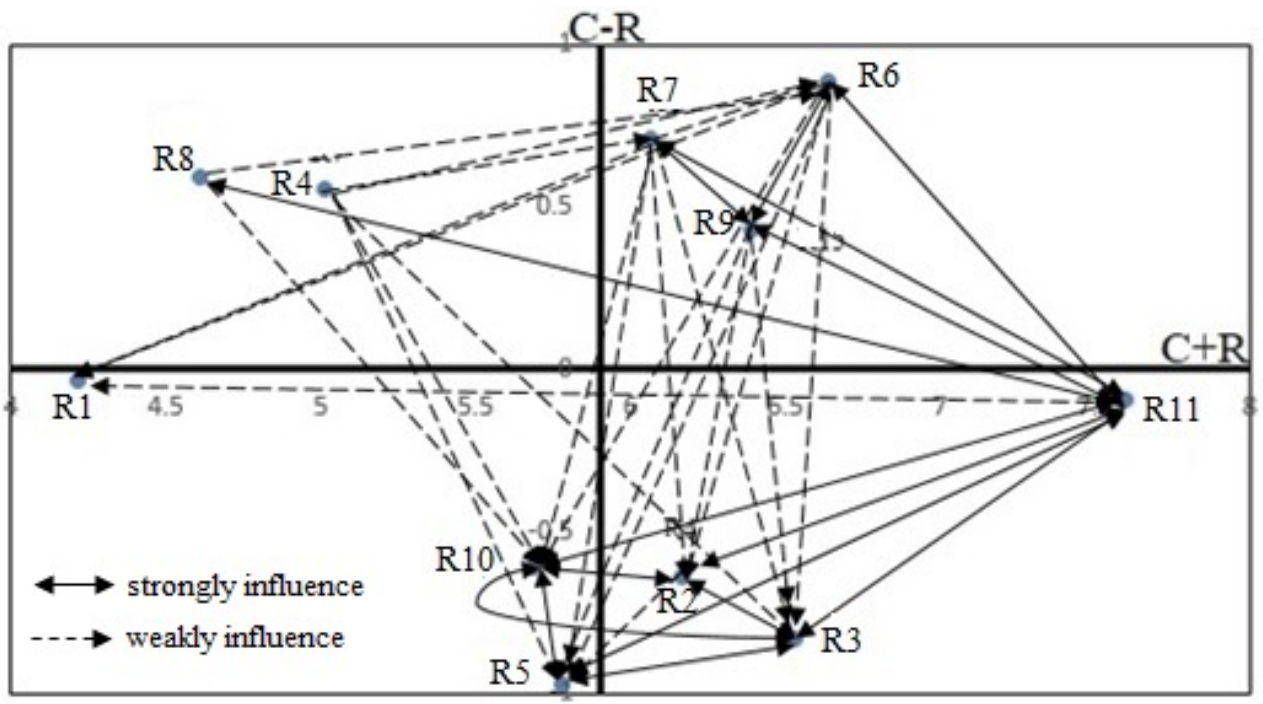

Fig. 5. Causal interrelationships graph

Based on the FDEMATEL results as shown in and Fig. 5, the causal interactions and the degrees of influence among the sustainability CRF's in the TSC are described as follows (Garg et al., 2017):

Strong relation, high prominence: the CRF's R6, R7, and R9 were the case group factors and were core factors that strongly influenced other factors. Thus, they were the driving sustainability CRF's in the TSC.

Strong relation, low prominence: the CRF's R2, R3, and R11 are slightly influenced by a few other CRFs. It is indicated that these are relatively dependent CRF's and come under effect group CRFs.

Weak relation, low prominence: the CRF's R1, R5, R10 are influenced by the other CRF's, confirming that R1, R5, R10 are the relatively dependent factors.

Weak relation, high prominence: the CRF's R8, and R4 are the cause group CRF's are that were influencing the remaining CRF's. Despite requiring improvement, the telecom sector operators could be directly improved because they came to under the cause group CRF's. 
It may be noted that "R6 (Difficulty in import technology and process)" is identified as a highly significant positive impact among all CRFs, confirming that the lack of knowledge and policies about the technology import from other nations reduces the confidence among the telecom operators in developing countries. In addition, R7 and R9 are also critical factors among the identified sustainability CRF's in the TSC, and is the second criterion to consider; the following CRF's are R8 and R4. These findings imply that these cause group CRF's may improve the effect group CRF's. If the telecom operators can set up the information related to new technology adoption, import the process to the supply chain members first, and then they could mainly focus on the customers' expectations.

\section{Discussions on results}

In addition, this study can compare both fuzzy ISM and fuzzy DEMATEL results to clearly understand or provide effective findings to the telecom operators. While if we can observe the fuzzy ISM network Fig. 2 in fuzzy ISM analysis and causal interrelationships graph Fig. 5 in the fuzzy DEMATEL analysis, there are few differences among approaches interactions. Those are government policies (laws and regulations) (R8) that have interactions with all other CRF's as per the fuzzy ISM analysis. The difficulty in import technology and process (R6), change of customer expectations (R7), and market competition (R9) were found to have high interactions with all other CRF's in the fuzzy DEMATEL analysis. In addition, the CRF's illegal activities (e.g.2G scams) (R1) and environmental pollution (R11) were found to have fewer interaction factors or minor CRF's in both method results. Moreover, the deep observation of the case and effect diagram as shown in Fig. 5 and fuzzy MICMAC matrix as shown in Fig. 4 has been confirming that the CRF R8 is the driving factor, while the dependence factors are illegal activities (e.g.2G scams) (R1) and environmental pollution (R11). Based on both fuzzy ISM- fuzzy DEMATEL results, we concluded that the common result is the impact of rapid change of technology (R4), government policies (laws and regulations) (R8), and difficulty in import technology and process (R6) is the major or driving CRF's, illegal activities (e.g.2G scams) (R1) and environmental pollution (R11) are the minor or dependent CRF's. Therefore, the telecom service providers must try to control the government policies (laws and regulations) (R8) and difficulty in import technology and process (R6) CRF's improve their SSCM.

As per the existing literature, supplier quality issues (R2) and lack of telecom infrastructure in semi-rural or rural areas (R5) have been cited as the key risk factor to accomplishing sustainability in the TSC (Ahmadi et al., 2020; Valinejad and Rahmani, 2018). Besides, government policies (laws and regulations) (R8), change of customer expectations (R7) CRF's can also be found as driving factors in recent research studies (Song et al., 2017; Loska and Higa, 2020; Daghfous et al., 2021). Gupta and Jain, (2019) found that illegal activities (e.g.2G scams) (R1) and environmental pollution (R11) are of low value and come under the top of the ISM network. In addition, this study result is disputing with other recent studies results as well. For example, Valinejad and Rahmani, (2018) determined that market competition (R9), the impact of rapid change of technology (R4) are the effect group factor, and the factors supplier quality issues (R2) are identified in the cause group. In other studies, Rezghdeh and Shokouhyar, (2020) identified that the CRF lack of education and technical skills (R3) as a linking factor and impact of rapid change of technology (R4) was considered as a minor risk factor.

\subsection{Implications for theory}

The primary contribution of the current study on the telecom sector SSCM is to establish a model of hierarchical structure and a detailed understanding of contextual interrelationships between CRFs. This study can contribute in two ways: those are theoretical contributions to the researchers and the society and practical contributions to the industry experts and the government to achieve sustainability.

From the theoretical point of view, the present study can be considered to be unique due to its novelty in developing a new hierarchical model for sustainability CRF's. An attempt was made to recognize 11 CRFs and construct the fuzzy ISM network and cause/effect graph for sustainable CRFs in TSC. Future, the risk assessment detailed an interrelated and combined subsystem, and both fuzzy analysis findings are providing more critical risk factors. Therefore, the telecom company management should be carefully evaluated and given the highest importance to essential CRF's. In addition, we have found that the present study results identified the critical risk factors and provide first-hand CRF's to the telecom operators. Subsequently, regarding the pervasiveness of the problems related to risk assessment for sustainability among the supply chain. the present analysis result is maybe useful for all levels involved among the TSC. Notably, the supply chain members of the telecom firms in developing countries. Apart from that, the present study is proposed a fuzzy hybrid methodology to risk assessment in supply chain management theory. The research results would significantly enhance the operational managers' understanding of the nature of interactions between risk management in TSC.

\subsection{Implications for practice}

This research study makes an important contribution by risk assessment using a hybrid fuzzy approach between the identified CRF's for SSCM through a systematic vision. The telecom executives may be adopting special measures to control, manage, and minimize economic risk. Besides that, the fuzzy ISM has the layout of the interactions and complexity between CRF's, this would allow telecom executives and policymakers to maximize efficiency while working with limited resources. The CRF government policies-laws and regulations (R8) are at the bottom of the fuzzy ISM hierarchy and difficulty in import 
technology and processes (R6) is in the cause group with the most driving power in the fuzzy DEAMTEL. Derived from the findings, the present study presumes that the two CRFs described above have the most influence risk for TSC. Consequently, this useful information may assist telecom sector executives and policymakers in making transparent decisions, as well as assessing their responsibility to address economic risk. The remaining CRFs in the fuzzy ISM network are caused by the high driving power CRFs and cause the interrelationships graph. This study would guide the present telecom service providers (middle stream) to manage these CRF's, this would allow the supply chain to run more efficiently and provide better services to their customers. As a result, it enables telecom companies to create a path to excellent corporate strategy for the long term, as well as a sustainability strategy across multiple dimensions, including economic, social, environmental, and political. Thus, these should enhance their learning experience while also attempting to capture opportunities for change (Li et al., 2020; Ullah et al., 2019). It would be helping the TSC channel members to enhance the sustainability measures and grape competitive advantage in the market. Moreover, the result of the present study and proposed hybrid fuzzy methodology on CRF's of sustainability may help offer quality services to their customers and the present firms develop a long-term and effective SSC strategy.

\section{Conclusions, limitations, and further studies}

This section elaborates on the results and solutions of the present research study. Sustainability has become a critical organizational issue for the developing telecom sectors, competing and standing out in an intense marketplace. Moreover, telecom companies cannot implement effective sustainability measures or procedures with limited capacity or resources. Similarly, the present study is advocating that the telecom firms should monitor and examine the CRF's for their sustainability measure among their supply chain. In addition, they could be observing the risk and evaluate such interactions from time to time within the organization by using the proposed hybrid fuzzy approach. Therefore, the present study may conduct the risk assessment of sustainability in the TSC through thorough review of literature and confirmation by decision-makers from the telecom sector in developing countries. Then, we have finalized the CRF's by utilizing the FDM. In addition, the current study sought to create a conceptual model on determined CRF's using fuzzy ISM and fuzzy DEMATEL followed by fuzzy MICMAC analysis. Hence, the risk assessment to achieving sustainability in the TSC, which does not appear in the existing literature

As part of the existing methodology, the present study investigated the interrelationships among the CRF's to achieve sustainability in the TSC. Which were analysed utilizing the hybrid approach. In addition, the combination of fuzzy ISM and fuzzy DEMATEL share several similar characteristics and provide effective results (Petrudi et al., 2018). In this study, while comparing both methods results to clearly understand or provide effective findings to the telecom operators. While if we can observe the fuzzy ISM network Fig. 3 in fuzzy ISM analysis and causal interrelationships graph Fig. 5 in the fuzzy DEMATEL analysis, there are few differences among approaches interactions. Those are government policies (laws and regulations) (R8) that have interactions with all other CRF's as per the ISM network. Where the difficulty in import technology and process (R6), Change of customer expectations (R7), and Market competition (R9) were found, high interactions with all other CRF's in the causal interrelationships graph. In addition, the CRF's illegal activities (e.g.2G scams) (R1) and environmental Pollution (R11) were found to have fewer interaction factors or minor CRF's in both method results.

This study has a few limitations that need to be acknowledged. The first limitation is the risk assessment is a complex construct. Moreover, the risk could vary from time to time, from sector to sector; this study does not examine every facet of all risk dimensions inside the TSC or in other industries. The study's second flaw is that it focuses primarily on developing countries, and the data was collected from the Indian telecom sector. Therefore, it is difficult to say how far the findings apply to developed countries or other countries on different continents. The last constraint is that the estimations of CRF interrelationships are reliant on concessions from decision-makers, which may make decision-making more challenging. In addition, this study can suggest future research. Future researchers may concentrate on a specific aspect of industry operations to assess risk assessment. Other sectors may have an impact on the CRFs' relationship and ranking, or different process and service characteristics may vary, resulting in different outcomes when utilizing alternative approaches like fuzzy ISM and DEMATEL or fuzzy DEMATEL and ISM. If ISM is combined with structural equation modelling (SEM), the results are said to be more accurate. Moreover, the present hierarchical structure model and cause/effect of the risk assessment is not statistically validated. Therefore, those analysis results need further confirmatory research to validate. So, this study suggests the cause/effect and the validity of future research can be assessed using a hierarchical structure model that can be considered as SEM. The other approach would be a repetition of the present research by utilizing the hybrid methodology instead of fuzzy ISM and fuzzy DEMATEL, which is more productive for a clearer idea of interactions between the risk dimensions. Finally, future academics will be able to grasp the functional gaps of the proposed hybrid fuzzy methodologies by combining SEM and fuzzy AHP to describe the clear relationships of risk dimensions for sustainability in the TSC.

\section{Acknowledgement}

This work was supported in part by the Ministry of Science and Technology, Taiwan (R.O.C.) under Grant MOST 110-2410H-324-003, and Chaoyang University of Technology under Grant 110F0021109. 


\section{References}

Afifa, M. M. A., \& Saleh, I. (2021). Management accounting systems effectiveness, perceived environmental uncertainty and companies' performance: the case of Jordanian companies. International Journal of Organizational Analysis. https://doi.org/10.1108/JAOC-10-2020-0165

Agbebi, M. (2018). China in Africa's telecom sector: opportunities for human capital development? A case of Huawei in Nigeria. Human Resource Development International, 21(5), 532-551. https://doi.org/10.1080/13678868.2018.1512232

Ahmadi, O., Mortazavi, S. B., Mahabadi, H. A., \& Hosseinpouri, M. (2020). Development of a dynamic quantitative risk assessment methodology using fuzzy DEMATEL-BN and leading indicators. Process Safety and Environmental Protection, 142, 15-44. https://doi.org/10.1016/j.psep.2020.04.038

Chaudhuri, A., Srivastava, S. K., Srivastava, R. K., \& Parveen, Z. (2016). Risk propagation and its impact on performance in food processing supply chain: a fuzzy interpretive structural modeling-based approach. Journal of Modelling in Management, 11(2), 660-693. https://doi.org/10.1108/JM2-08-2014-0065

Chauhan, A. S., Badhotiya, G. K., Soni, G., \& Kumari, P. (2020). Investigating interdependencies of sustainable supplier selection criteria: an appraisal using ISM. Journal of Global Operations and Strategic Sourcing. https://doi.org/10.1108/JGOSS-02-2019-0017

Chen, W. K., Nalluri, V., Ma, S., Lin, M. M., \& Lin, C. T. (2021). An Exploration of the Critical Risk Factors in Sustainable Telecom Services: An Analysis of Indian Telecom Industries. Sustainability, 13(2), 445. https://doi.org/10.3390/su13020445

Chowdhury, N. A., Ali, S. M., Mahtab, Z., Rahman, T., Kabir, G., \& Paul, S. K. (2019). A structural model for investigating the driving and dependence power of supply chain risks in the readymade garment industry. Journal of Retailing and Consumer Services, 51, 102-113. https://doi.org/10.1016/j.jretconser.2019.05.024

Daghfous, A., Qazi, A., \& Khan, M. S. (2021). Incorporating the risk of knowledge loss in supply chain risk management. The International Journal of Logistics Management. https://doi.org/10.1108/IJLM-06-2020-0225

Dawood, K. A., Sharif, K. Y., Ghani, A. A., Zulzalil, H., Zaidan, A. A., \& Zaidan, B. B. (2021). Towards a unified criteria model for usability evaluation in the context of open source software based on a fuzzy Delphi method. Information and Software Technology, 130, 106453. https://doi.org/10.1016/j.infsof.2020.106453

Dewangan, D. K., Agrawal, R., \& Sharma, V. (2017). Enablers of eco-innovation to enhance the competitiveness of the Indian manufacturing sector: an integrated ISM-fuzzy MICMAC approach. International Journal of Business Innovation and Research, 13(4), 475-501. https://doi.org/10.1504/IJBIR.2017.085103

Digalwar, A., Raut, R. D., Yadav, V. S., Narkhede, B., Gardas, B. B., \& Gotmare, A. (2020). Evaluation of critical constructs for measurement of sustainable supply chain practices in lean-agile firms of Indian origin: A hybrid ISM-ANP approach. Business Strategy and the Environment, 29(3), 1575-1596. https://doi.org/10.1002/bse.2455

Dike, M. C., \& Rose, E. L. (2017). Internationalization of mobile telecommunications: a systematic literature review. Review of International Business and Strategy. https://doi.org/10.1108/RIBS-01-2017-0004

Elgharbawy, A. (2020). Risk and risk management practices: A comparative study between Islamic and conventional banks in Qatar. Journal of Islamic Accounting and Business Research. https://doi.org/10.1108/JIABR-06-2018-0080

Farooque, M., Jain, V., Zhang, A., \& Li, Z. (2020). Fuzzy DEMATEL analysis of barriers to Blockchain-based life cycle assessment in China. Computers \& Industrial Engineering, 147, 106684. https://doi.org/10.1016/j.cie.2020.106684

Ganguly, K. (2019). Establishing link between quality management and supply chain risk management: A fuzzy AHP approach. The TQM Journal. https://doi.org/10.1108/TQM-05-2019-0125

Garg, C., Sharma, A., \& Goyal, G. (2017). A hybrid decision model to evaluate critical factors for successful adoption of GSCM practices under fuzzy environment. Uncertain Supply Chain Management, 5(1), 59-70. DOI: $10.5267 /$ j.uscm.2016.7.002

Gouda, S. K., \& Saranga, H. (2018). Sustainable supply chains for supply chain sustainability: impact of sustainability efforts on supply chain risk. International Journal of Production Research, 56(17), 5820-5835. https://doi.org/10.1080/00207543.2018.1456695

Gupta, P., \& Jain, N. (2019). Signalling role of $2 \mathrm{G}$ scam investigation on stock market returns of select telecom companies in India. International Journal of Public Sector Performance Management, 5(3-4), 370-383. https://doi.org/10.1504/IJPSPM.2019.101071

Hameed, H. B., Ali, Y., \& Petrillo, A. (2020). Environmental risk assessment of E-waste in developing countries by using the modified-SIRA method. Science of The Total Environment, 733, 138525. https://doi.org/10.1016/j.scitotenv.2020.138525

Herlina, M., \& Saputra, N. (2021). Does motivation play moderating role on organizational citizenship behavior? Evidence from Indonesian telecommunication firms. Management Science Letters, 11(5), 1667-1676. DOI: $10.5267 /$ j.msl.2020.12.004

Izogo, E. E. (2017). Customer loyalty in telecom service sector: the role of service quality and customer commitment. The TQM Journal. https://doi.org/10.1108/TQM-10-2014-0089

Jain, R. K., Gonela, S. K., \& Raghavendra, B. T. (2020). Telecom in India in 2017: Uncertainty Calling. Asian Journal of Management Cases, 0972820120927184.https://doi.org/10.1177/0972820120927184

Jain, V., \& Raj, T. (2021). Study of issues related to constraints in FMS by ISM, fuzzy ISM and TISM. International Journal of Industrial and Systems Engineering, 37(2), 197-221. https://doi.org/10.1504/IJISE.2021.112876 
Kara, M. E., Frrat, S. Ü. O., \& Ghadge, A. (2020). A data mining-based framework for supply chain risk management. Computers \& Industrial Engineering, 139, 105570. https://doi.org/10.1016/j.cie.2018.12.017

Kausar, K., Garg, D., \& Luthra, S. (2017). Key enablers to implement sustainable supply chain management practices: An Indian insight. Uncertain Supply Chain Management, 5(2), 89-104. DOI: 10.5267/j.uscm.2016.10.005

Khalifa, N., Abd Elghany, M., \& Abd Elghany, M. (2021). Exploratory research on digitalization transformation practices within supply chain management context in developing countries specifically Egypt in the MENA region. Cogent Business \& Management, 8(1), 1965459. https://doi.org/10.1080/23311975.2021.1965459

Khot, S., \& Thiagarajan, S. (2019). Resilience and sustainability of supply chain management in the Indian automobile industry. International Journal of Data and Network Science, 3(4), 339-348. DOI: 10.5267/j.ijdns.2019.4.002

Kundu, G. K. (2021). Modeling the enablers of project-based learning: an ISM-Fuzzy MICMAC approach. International Journal of Quality \& Reliability Management. https://doi.org/10.1108/IJQRM-08-2020-0273

Kusrini, N., \& Maswadi, M. (2021). The performance improvement of sustainable palm oil supply chain management after COVID-19: Priority indicators using F-AHP. Uncertain Supply Chain Management,9(2), 227-236. DOI: $10.5267 /$ j.uscm.2021.3.010

Li, X., Han, Z., Zhang, R., Zhang, Y., \& Zhang, L. (2020). Risk assessment of hydrogen generation unit considering dependencies using integrated DEMATEL and TOPSIS approach. International Journal of Hydrogen Energy, 45(53), 29630-29642. https://doi.org/10.1016/j.ijhydene.2020.07.243

Loska, D., \& Higa, J. (2020). The risk to reconstitution: supply chain risk management for the future of the US Air Force's organic supply chain. Journal of Defense Analytics and Logistics. https://doi.org/10.1108/JDAL-03-2019-0005

Luthra, S., \& Mangla, S. K. (2018). When strategies matter: Adoption of sustainable supply chain management practices in an emerging economy's context. Resources, Conservation and Recycling, 138, 194-206. https://doi.org/10.1016/j.resconrec.2018.07.005

Meehan, J., \& Pinnington, B. D. (2021). Modern slavery in supply chains: insights through strategic ambiguity. International Journal of Operations \& Production Management. https://doi.org/10.1108/IJOPM-05-2020-0292

Meethom, W., \& Koohathongsumrit, N. (2020). A decision support system for road freight transportation route selection with new fuzzy numbers. foresight. https://doi.org/10.1108/FS-10-2019-0090

Muneeb, F. M., Yazdi, A. K., Wanke, P., Yiyin, C., \& Chughtai, M. (2020). Critical success factors for sustainable entrepreneurship in Pakistani Telecommunications industry: a hybrid grey systems theory/best-worst method approach. Management Decision. https://doi.org/10.1108/MD-08-2019-1133

Munyimi, T. F., \& Chari, D. F. (2018). The role of buyer-supplier relationships in achieving economic sustainability in the private telecommunication sector in Zimbabwe. Cogent Business \& Management, 5(1), 1540917. https://doi.org/10.1080/23311975.2018.1540917

Nasrollahi, M., Fathi, M. R., Sobhani, S. M., Khosravi, A., \& Noorbakhsh, A. (2021). Modeling resilient supplier selection criteria in desalination supply chain based on fuzzy DEMATEL and ISM. International Journal of Management Science and Engineering Management, 1-15. https://doi.org/10.1080/17509653.2021.1965502

Norrman, A., \& Wieland, A. (2020). The development of supply chain risk management over time: revisiting Ericsson. International Journal of Physical Distribution \& Logistics Management. https://doi.org/10.1108/IJPDLM-072019-0219

Ortiz-Barrios, M., Cabarcas-Reyes, J., Ishizaka, A., Barbati, M., Jaramillo-Rueda, N., \& de Jesús Carrascal-Zambrano, G. (2020). A hybrid fuzzy multi-criteria decision-making model for selecting a sustainable supplier of forklift filters: a case study from the mining industry. Annals of Operations Research, 1-39. https://doi.org/10.1007/s10479-020-03737-y

Paksoy, T., Çalik, A., Yildizbaşi, A., \& Huber, S. (2019). Risk management in lean \& green supply chain: A novel fuzzy linguistic risk assessment approach. In Lean and green supply chain management (pp. 75-100). Springer, Cham. https://doi.org/10.1007/978-3-319-97511-5 3

Panjehfouladgaran, H., \& Lim, S. F. W. (2020). Reverse logistics risk management: identification, clustering and risk mitigation strategies. Management Decision. https://doi.org/10.1108/MD-01-2018-0010

Petrudi, S., Abdi, M., \& Goh, M. (2018). An integrated approach to evaluate suppliers in a sustainable supply chain. Uncertain Supply Chain Management, 6(4), 423-444. DOI: 10.5267/j.uscm.2017.12.003

Pramod, V. R., Banwet, D. K., \&Sarma, P. R. S. (2016). Understanding the barriers of service supply chain management: an exploratory case study from Indian telecom industry. Opsearch, 53(2), 358-374. https://doi.org/10.1007/s12597-0150234-5

Ramesh, K. T., Sarmah, S. P., \& Tarei, P. K. (2019). An integrated framework for the assessment of inbound supply risk and prioritization of the risk drivers: A real-life case on electronics supply chain. Benchmarking: An International Journal. https://doi.org/10.1108/BIJ-03-2019-0119

Reichling, M., \& Otto, T. (2017). The environmental impact of the new economy: Deutsche Telekom, telecommunications services and the sustainable future. In The ecology of the new economy (pp. 119-129). Routledge. https://doi.org/10.4324/9781351282048

Rezghdeh, K., \& Shokouhyar, S. (2020). A six-dimensional model for supply chain sustainability risk analysis in telecommunication networks: a case study.Modern Supply Chain Research and Applications. https://doi.org/10.1108/MSCRA-09-2019-0018

Sacco, F. M. (2020). The evolution of the telecom infrastructure business. In Disruption in the Infrastructure Sector (pp. $87-$ 148). Springer, Cham. https://doi.org/10.1007/978-3-030-44667-3_4 
Saglam, Y. C., Çankaya, S. Y., \& Sezen, B. (2020). Proactive risk mitigation strategies and supply chain risk management performance: an empirical analysis for manufacturing firms in Turkey. Journal of Manufacturing Technology Management. https://doi.org/10.1108/JMTM-08-2019-0299

Shakerian, M., Choobineh, A., Jahangiri, M., Alimohammadlou, M., Nami, M., \& Hasanzadeh, J. (2020). Interactions among Cognitive Factors Affecting Unsafe Behavior: Integrative Fuzzy DEMATEL ISM Approach. Mathematical Problems in Engineering, 2020. https://doi.org/10.1155/2020/8952624

Shanker, S., \& Barve, A. (2021). Analysing sustainable concerns in diamond supply chain: a fuzzy ISM-MICMAC and DEMATEL approach. International Journal of Sustainable Engineering, 1-17. https://doi.org/10.1080/19397038.2020.1862351

Singh, S., \& Guha, M. (2018). Experiential learning: Analyzing success and failures in Indian telecom sector. Benchmarking: An International Journal. https://doi.org/10.1108/BIJ-07-2017-0199

Song, W., Ming, X., \& Liu, H. C. (2017). Identifying critical risk factors of sustainable supply chain management: A rough strength-relation analysis method. Journal of Cleaner Production, 143, 100-115. https://doi.org/10.1016/j.jclepro.2016.12.145

Srivastava, A., \& Dashora, K. (2021). A Fuzzy ISM approach for modeling electronic traceability in agri-food supply chain in India. Annals of Operations Research, 1-19. https://doi.org/10.1007/s10479-021-04072-6

Talib, F., \& Rahman, Z. (2017). Modeling the barriers of Indian telecom services using ISM and MICMAC approach. Journal of Asia Business Studies https://doi.org/10.1108/JABS-11-2015-0196

Ullah, I., Raza, B., Malik, A. K., Imran, M., Islam, S. U., \& Kim, S. W. (2019). A churn prediction model using random forest: analysis of machine learning techniques for churn prediction and factor identification in telecom sector. IEEE Access, 7, 60134-60149. doi: 10.1109/ACCESS.2019.2914999

Valinejad, F., \& Rahmani, D. (2018). Sustainability risk management in the supply chain of telecommunication companies: A case study. Journal of Cleaner Production, 203, 53-67. https://doi.org/10.1016/j.jclepro.2018.08.174

Vij, M. (2019). The emerging importance of risk management and enterprise risk management strategies in the Indian hospitality industry: Senior managements' perspective. Worldwide Hospitality and Tourism Themes. https://doi.org/10.1108/WHATT-04-2019-0023

Wagner, B. (2015). Implementing and managing economic, social and environmental efforts of business sustainability. Management of Environmental Quality: An International Journal,26(2), 195-213. https://doi.org/10.1108/MEQ-09-2013-0099

Wang, W., Liu, X., Qin, Y., Huang, J., \& Liu, Y. (2018). Assessing contributory factors in potential systemic accidents using AcciMap and integrated fuzzy ISM-MICMAC approach. International journal of industrial ergonomics, 68, 311-326. https://doi.org/10.1016/j.ergon.2018.08.011

Warfield, J. N. (1974). Developing interconnection matrices in structural modeling. IEEE Transactions on Systems, Man, and Cybernetics, 1, 81-87. 10.1109/TSMC.1974.5408524

Yadav, G., \& Desai, T. N. (2017). Analyzing lean six sigma enablers: a hybrid ISM-fuzzy MICMAC approach. The TQM Journal. https://doi.org/10.1108/TQM-04-2016-0041

Yalla, S. P., Bhattacharyya, S. S., \& Jain, K. (2018). Impact of regulatory announcements on systemic risk in the Indian telecom sector. International Journal of Emerging Markets. https://doi.org/10.1108/IJoEM-08-2017-0307 


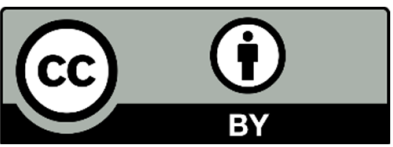

(C) 2022 by the authors; licensee Growing Science, Canada. This is an open access article distributed under the terms and conditions of the Creative Commons Attribution (CCBY) license (http://creativecommons.org/licenses/by/4.0/). 